\title{
Die gehörnte Gebärmutter
}

Iris Ritzmann

Prof. Dr. med. et lic. phil., Mitglied der Redaktion Medizingeschichte

Schön sollte es sein, aber auch lustig und erst noch Trost spenden, das bekannteste Werk des Zürcher Stadtchirurgen und Theatermachers Jacob Ruf. 1554 erschien es erstmals unter dem Titel Ein schön lustig Trostbüchle von den empfengknussen unnd geburten der menschen [...] zuo trost allen gebärenden frouwen, und eigentlichem bericht der Hebammen. Der Inhalt entspricht dem damaligen Prüfungsstoff der Hebammen, denn Ruf leitete ihre Ausbildung. Das Trostbüchle steht damit für einen Paradigmenwechsel in der Geburtshilfe: Das von Männern entwickelte theoretische Wissen über den weiblichen Körper wurde im Lauf der Frühen Neuzeit zur Bedingung, den Beruf der Hebamme ausüben zu können, während die Weitergabe der praktischen Geburtshilfe von Frau zu Frau an Bedeutung verlor.

Das ganze Werk ist mit zahlreichen prachtvollen Kupferstichen des noch blutjungen Künstlers Jost Amman ausgestattet. Sie zeigen Geburtsszenen und Wundergeburten, als grosses Novum aber auch geburtshilfliche Instrumente und die Keimentwicklung. Im Zentrum der anatomischen Abhandlung steht die Darstellung der «Bärmutter», der Gebärmutter also.

Der Kupferstich, hier aus der deutschen Zweitauflage von 1569, gibt den Blick in die weibliche Bauchhöhle frei. Oben ist das Zwerchfell sichtbar, es folgen die Nieren mit Harnleitern und zur Seite geschobener Blase. Im Hintergrund verlaufen die beiden grossen blutführenden Bauchgefässe mit ihren fein verästelten Ausläufern - man ging noch nicht von einem Blutkreislauf aus. Die untere Hälfte des Kupferstichs dominiert die Darstellung der weiblichen Fortpflanzungsorgane: Zwei seltsam brombeerförmige Eierstöcke und die kugelrunde Gebärmutter, die auf einer Scheide mit kunstvoll gelocktem Schamhaar thront. Durch einen Kreuzschnitt lässt sich in ihrem Innern ein rückwärts gewandter Fötus erkennen.

Was sich hinter der Gebärmutter nach links und rechts schwingt, beschreibt Ruf als «zwey hörner, die band der bärmuoter genannt, mit welchem sy gebunden und bevestiget wirdt, zuo beiden syten an den rügkgrat angehefft.» Woher stammt diese Vorstellung? Galen ent-

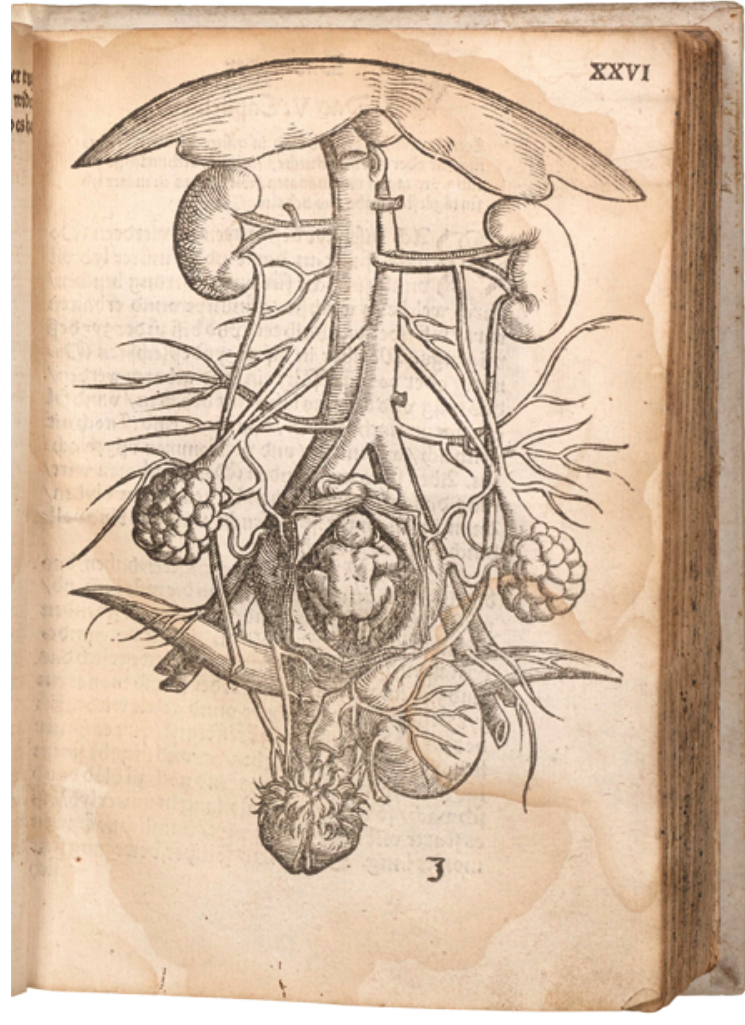

Jacob Ruf: Weibliche Bauchhöhlenorgane, Blatt XXVI r, zweite deutsche Aufl. Zürich 1569, Sammlung Dr. Franz Käppeli.

warf in der Spätantike die bis dahin umfassendste menschliche Anatomielehre. Seine Erkenntnisse basierten jedoch auf Tiersektionen, weshalb ihm mehrere Fehler unterliefen, so auch die Annahme, dass die Gebärmutter zwei Hörner aufweise. Obwohl bereits seit 1300 menschliche Leicheneröffnungen zu Lehrzwecken erlaubt waren und durchgeführt wurden, wichen die Anatomen noch lange nicht von Galens Beschreibungen ab. Die gehörnte Gebärmutter blieb bis in die Neuzeit hinein in chirurgischen und anatomischen Lehrbüchern erhalten.

Bildnachweis

Museum für medizinhistorische Bücher Muri (mmbm.ch) 